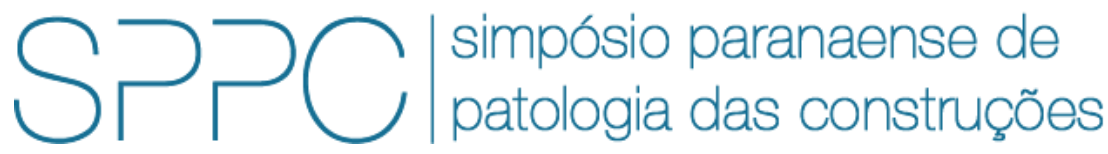

ISSN 2526-7248 artigo 2SPPC1021, pp. 253-265, 2017

\title{
Influência do agregado reciclado na durabilidade do concreto: uma revisão da bibliografia
}

\author{
Patricia Kruger ${ }^{1}$, Eduardo Pereira ${ }^{2}$ e Adriana S.A. Chinelatto ${ }^{3}$ \\ 1 Doutoranda, Universidade Estadual de Ponta Grossa, pkruger@uepg.br \\ 2 Doutor, Universidade Estadual de Ponta Grossa, eduardopereira@uepg.br \\ 3 Doutora, Universidade Estadual de Ponta Grossa, adrianachinelatto@gmail.com
}

\begin{abstract}
Resumo: No Brasil, as edificações são concebidas para durar muitos anos, porém devido à falta de manutenção, aumento da demanda populacional ou mudanças nas características urbanas onde está inserida, sua vida útil muitas vezes é reduzida. Tendo em vista que os recursos naturais não são renováveis e que novas edificações demandam geração de agregados para sua produção, uma proposta que já vem sendo estudada é a utilização destes resíduos de construções e demolições transformados em agregados reciclados para construção. $O$ presente artigo apresenta uma conceituação sobre a propriedade de durabilidade do concreto, correlacionando-a com as características dos agregados constituintes. De forma análoga, está apontado através de diversos estudos, como estas características influenciam diferenciadamente os agregados reciclados. Observa-se que conhecendo o comportamento apresentado pelos agregados reciclados, é possível fazer o monitoramento adequado do gerenciamento e beneficiamento deste material. Ao se controlar as características do RCD, consequentemente aumenta-se o controle das propriedades do concreto com ele confeccionado. Conclui-se então após esta revisão da literatura que a produção de concretos com boa durabilidade é um objetivo tangível.
\end{abstract}

Palavras-chave: durabilidade, concreto, agregado reciclado, RCD.

Abstract: In Brazil, buildings are designed to last for many years. However, due to lack of maintenance, increased population demand or changes in the urban characteristics where they are inserted, their service life is often reduced. Since natural resources are not renewable and new buildings require generation of aggregates for their production, a proposal that has already been studied is the use of these construction and demolition waste transformed into recycled aggregates for construction. This article presents a conceptualization on the concrete durability property, correlating it with the characteristics of its constituent aggregates. In an analogous way, it points out through several studies, how these characteristics influence the recycled aggregates in different ways. It is observed that knowing the behavior presented by the recycled aggregates, it is possible monitor in a proper way the management and processing of this material. When the CDW characteristics are controlled, consequently an increase in the control of the properties of the concrete made with it is obtained. The conclusion of this literature review is that the production of concrete with good durability is a tangible objective.

Keywords: durability, concrete, recycled aggregate, CDW. 


\section{Introdução}

As edificações em concreto armado devem contemplar as principais características desejáveis para a engenharia, como resistência, estabilidade dimensional e durabilidade. O presente artigo abordará mais especificamente a durabilidade do concreto interligada as características dos agregados, porém não deixará de contemplar a importância que as outras duas fases do concreto (matriz cimenticia hidratada e interface matriz/agregado) representam nesta propriedade. Primeiramente será feita uma abordagem a respeito da durabilidade de concretos confeccionados com agregados naturais, citando conceitos já consolidados no meio científico, para então correlacionar com as particularidades encontradas nos estudos de concretos confeccionados com agregados reciclados, provenientes de resíduos de construção e demolição (RCD).

A durabilidade é influenciada pela dosagem e pelo comportamento do concreto no estado fresco e endurecido. Caracterísiticas dos agregados como porosidade, massa específica, forma e textura dos agregados, resistência, módulo de elasticidade, absorção e teor de impurezas influenciam neste comportamento [1].

$\mathrm{ACl}$ Committee 201 [2], define durabilidade do concreto como sendo a capacidade de resistir à ação de intempéries, ataque químico, abrasão ou qualquer outro tipo processo de deterioração. Um concreto durável preservará sua forma, qualidade e desempenho quando exposto ao ambiente de uso para o qual foi projetado. Para Paulon [3] existem três propriedades essenciais do concreto, resistência mecânica, porosidade e durabilidade. Para Mehta e Monteiro [1], do ponto de vista da resistência, a dependência entre relação água/cimento e porosidade é sem dúvida, o fator mais importante, porque, além de outros, afeta a porosidade da matriz e a zona de transição pasta/agregado.

Um concreto impermeável seria o ideal para evitar a ação de agentes de deterioração, porém esta característica pode ser melhorada, mas não totalmente obtida. A permeabilidade é definida como a facilidade com que um fluido sob pressão pode fluir através de um sólido e é determinada pelo tamanho e a continuidade dos poros na microestrutura.

Para Andrade [4] muitas manifestações patológicas nas estruturas de concreto são provenientes dos materiais constituintes. Diante disto observa-se que cada material deve ser controlado para obtenção de um concreto mais durável. O cimento Portland deve ser avaliado quanto aos aspectos físicos (resistência à compressão, finura, início e fim de pega, expansibilidade, calor de hidratação) e aspectos químicos (composição, percentual de adição, perda ao fogo, resíduo insolúvel, teores de $\mathrm{C}_{3} \mathrm{~A}$ e de álcalis). Os agregados também devem ser avaliados quanto a aspectos físicos (distribuição granulométrica, formato dos grãos, material pulverulento) e aspectos químicos (análise petrográfica, reatividade potencial). No que se referem à armadura, os aspectos a serem analisados são patamar de escoamento, limite de resistência, alongamento mínimo, desbitolamento e dobramento.

Segundo Sbrighi Neto [5], os agregados usados habitualmente na produção do concreto tem resistência mecânica muito superior à do próprio concreto, raramente se constituindo num fator limitante e a ruptura do concreto é determinada pelas outras duas fases. Há, entretanto, outras características do agregado além da resistência, como dimensão, forma, textura superficial, granulometria (distribuição 
do tamanho das partículas) e mineralogia das partículas de agregado que influenciarão as características da zona de transição na interface e, portanto, afetarão a resistência do concreto [1].

\section{Agregado reciclado e sua influência na durabilidade do concreto}

Os artigos pesquisados sobre agregados reciclados abordam principalmente as características do agregado e sua influência na produção de concretos, analisando propriedades no estado fresco (consistência, trabalhabilidade) e no estado endurecido (resistência a compressão/tração, retração e módulo de elasticidade). Informações a respeito da forma de produção do agregado reciclado, bem como os contaminantes que podem ter nesta fase inicial, também foram abordados e serão apresentados neste trabalho. Como mencionado anteriormente, a análise do comportamento da zona de transição pasta/agregado (ZT) quando do uso de agregado reciclado mostrou ser um ponto diferenciado nesta pesquisa, bem como a característica única do agregado reciclado em ter argamassa aderida em sua superfície.

\subsection{Características do agregado reciclado}

A durabilidade do concreto está diretamente relacionada a propriedades tais como porosidade, massa específica, forma e textura dos grãos, resistência, módulo de elasticidade, absorção e teor de impurezas. Desta forma, será apresentado aqui o comportamento do agregado reciclado com relação a estas propriedades.

A porosidade afeta o desempenho mecânico do concreto e ambos estão relacionados com a relação $\mathrm{a} / \mathrm{c}$, pois quanto maior $0 \mathrm{a} / \mathrm{c}$, maior 0 aumento da porosidade e isto acarreta em um enfraquecimento progressivo da matriz cimentícia [1]. Pode-se considerar que a resistência à compressão, a resistência à abrasão e o módulo de deformação são propriedades interligadas e são influenciadas pela porosidade do agregado [4].

A porosidade do agregado graúdo afeta o módulo de elasticidade do concreto, pois determina sua rigidez e controla a capacidade de o agregado restringir a deformação da matriz. Agregados densos tem alto módulo de elasticidade. A dimensão, forma, textura superficial, distribuição granulométrica e composição mineralógica do agregado podem influenciar a fissuração na zona de transição da interface e, assim, afetar a forma da curva tensão-deformação [1].

A porosidade do agregado acaba sendo mais relevante que a natureza mineral do RCD que lhe deu origem e afeta diretamente suas propriedades mecânicas (resistência e módulo, apresentando uma redução dos valores de até $50 \%$ ) e físicas (absorção, aumento de até 14\% e densidade, redução de 20\%) [6;7]. Os agregados podem ter seus poros completamente fechado no interior do sólido ou podem ser superficiais e seus tamanhos poder ser muito variados. A água e as partículas de cimento da pasta podem penetrar nestes poros e a profundidade de penetração dependerá das dimensões, continuidade e volume total dos poros, bem como da finura do cimento [6]. Quanto à relação a/c, cabe lembrar que quanto maior for esta relação, menor é a quantidade de cimento nas misturas para se combinar com a água existente, e isto faz com que aumente a porosidade do concreto, gerando redução da massa específica de até $16 \%$ [8]. 
Segundo Gómez-Soberón [10], quando utilizado proporções de agregados de RCD (ARC) em substituição a agregados naturais (AN), verifica-se uma correlação com o volume total e o tamanho do poro do agregado (2,82 \% para AN contra $14,86 \%$ para ARC). Esta influência ocorre de forma mais significativa em concretos nas primeiras idades e vai diminuindo com o tempo. Isto é atribuído à cristalização de produtos novos que reduzem tanto o número, quanto o tamanho dos poros. Quanto maior o grão do agregado, maior é a porosidade incorporada à mistura, portanto, maior é a redução da massa específica da mesma. A elevada quantidade de argamassa aderida à partícula de tijolo de argila triturada leva a uma diminuição próxima a $20 \%$ na densidade de partículas e a um aumento no valor de absorção de água de $14 \%$ $[6 ; 11]$.

A absorção de água em concreto está relacionada ao total de poros permeáveis na estrutura e o índice de vazios está relacionado a todos os poros existentes. De forma indireta, o conhecimento desta estrutura de poros permite prever a durabilidade de um concreto, uma vez que possibilita o conhecimento da forma pela qual os agentes agressivos se difundirão ou penetrarão através do interior da massa de concreto [12].

A quantidade total de água que entra na composição do concreto é a somatória da quantidade de água absorvida pelo agregado, da água superficial no agregado e da água na pasta de cimento. A grande quantidade de água que o material reciclado pode absorver depende de fatores como a condição inicial de umidade do agregado, o tempo de permanência de contato deste com a água, se o agregado entra em contato primeiro somente com a água, ou com a pasta de cimento. Este último fator, se o agregado for utilizado seco, pode fazer com que as partículas fiquem imediatamente cobertas de pasta de cimento, impedindo a entrada de água necessária à saturação do agregado [6].

Leite [8] demonstrou que a absorção de água varia de acordo com a natureza do material. Para a grande maioria dos materiais cerâmicos altamente porosos, como tijolos e telhas, a absorção do RCD aumenta significativamente, de $1 \%$ para $8,6 \%$ para o agregado miúdo e de $0,3 \%$ para $4,95 \%$ para o agregado graúdo. Lye et al. [13] desenvolveram uma pesquisa abrangendo 286 publicações de onde confirmam que agregado reciclado possui massa específica menor e absorção maior que os agregados naturais. Isto mostra a diferença na qualidade dos dois conjuntos de agregados, sugerindo que a retração do concreto deve aumentar com o uso de agregado reciclado de concreto em proporção ao seu conteúdo. Outra análise extraída do artigo de Lye et al. [13] é que agregados reciclados de materiais cimentícios apresentam predominância de grãos cúbicos, enquanto que agregados reciclados de materiais cerâmicos menos porosos, apresentam principalmente grãos lamelares.

As partículas alongadas de agregados reciclados diminuem a trabalhabilidade de concretos, uma vez que exigem uma maior quantidade de água e areia. Isso reduz a resistência do concreto, e também requer uma quantidade excessiva de cimento. No caso de agregados reciclados, a forma da partícula é determinada em grande parte pelo equipamento de britagem. Agregados britados são conhecidos pela angulosidade de sua forma e pela aspereza de sua superfície. Assim, o uso destes agregados deve merecer sempre estudo rigoroso para determinação do traço do concreto de modo a otimizar seu desempenho [5]. Concretos produzidos com agregados com forma angular quando comparados a agregados lamelares, induzem 
a um maior consumo de cimento quando se pretende manter determinada consistência [12].

Comparando a forma do grão, observa-se que a textura muito lisa, especialmente nos agregados graúdos, pode induzir uma aderência menor entre a pasta de cimento e a superfície do agregado, chegando, em alguns casos, a prejudicar o nível de resistência à tração do concreto especialmente nas primeiras idades [5]. A existência de água de exsudação e a sua influência na zona de interface em torno do agregado são muito importantes. Quanto maiores forem as proporções de partículas lamelares e alongadas dos agregados, maior será a tendência da água de acumular-se em películas próximas às partículas, tornando mais fraca a pasta de cimento na região de interface [3].

Outra característica analisada em agregados é a textura superficial, que é definida pelo grau com que a superfície do agregado é considerada lisa ou áspera. Depende da dureza, tamanho do grão, porosidade da rocha matriz e sua subsequente exposição à força de atrito. Durante as primeiras idades, a resistência do concreto (particularmente a resistência à flexão) pode ser afetada pela textura do agregado, pois é mais áspera, propiciando a formação de aderência física mais forte entre a pasta de cimento e o agregado. Em idades mais avançadas, com 0 desenvolvimento de uma aderência química mais forte entre a pasta e o agregado, esse efeito pode ser minimizado. Comparadas às partículas lisas e arredondadas, as partículas de textura áspera, angulosas e alongadas necessitam de mais pasta de cimento para produzir misturas de concreto trabalháveis [1].

Observou-se que uma mistura de concreto contendo um agregado de textura rugosa ou agregado britado apresenta resistência mais alta (especialmente a resistência à tração) nas primeiras idades do que um concreto correspondente contendo agregado liso ou que sofreu intemperismo natural com mineralogia similar. Uma ligação física mais forte entre o agregado e a pasta de cimento hidratado é dita como a responsável por isso [1].

O agregado reciclado de resíduo de construção e demolição (RCD) pode ter uma variabilidade grande em sua constituição. Estes podem ser constituídos de parcelas de concreto, argamassa e cerâmica e apresentarem diversas granulometrias. 0 processo de produção do concreto, bem como o processo de britagem determina as características físicas, mecânicas e químicas dos agregados produzidos e os agregados miúdos são mais afetados do que os graúdos [14]. A granulometria, a quantidade de argamassa aderida, os contaminantes e impurezas são influenciadas pelo processo de britagem adotado. Segundo Hansen citado por Buttler [9], a utilização do britador de mandíbula fornece uma melhor distribuição granulométrica do agregado reciclado para a produção do concreto. O britador de cones é adequado para ser utilizado como um britador secundário, já o britador de impacto fornece uma melhor distribuição granulométrica do agregado reciclado para ser empregado em sub-bases e bases de rodovias. Segundo Exteberria et al. [14], neste tipo de britador há uma redução de argamassa aderida.

A remoção de pasta de cimento e outras fases porosas é importante para melhorar a qualidade da areia reciclada e ampliar o mercado de agregados reciclados, pois a argamassa aderida em agregados tem menor resistência do que os agregados convencionais e a nova pasta [14]. Segundo Ulsen et al. [15], os estudos de separabilidade realizados em escala de laboratório indicam que tanto a densidade quanto a separação magnética foram eficazes na redução do teor de pasta de 
cimento e partículas de cerâmica vermelha residual (80\% para a densidade e 60\% para a separação magnética). Em Vegas et al. [16], foi utilizado o tratamento de triagem utilizando o infravermelho próximo (NIR) e as frações de agregados que podem trazer redução no desempenho dos concretos com eles fabricados foram reduzidas e até eliminadas. Como resultado da triagem NIR, a qualidade dos agregados mistos reciclados foi melhorada não apenas no nível de constituintes indesejáveis (redução de até $22 \%$ de impurezas), mas também no que se refere ao impacto no ambiente (lixiviação fortemente reduzida de sulfato, chegando a valores de redução de $90 \%$ ) e ao teste químico (níveis reduzidos de sulfato total e solúvel, com redução de 3,3\% para 0,9\%) [16].

A camada de argamassa aderida é responsável pela alta porosidade do agregado, alta absorção e redução da massa específica. As propriedades mecânicas do concreto reciclado são influenciadas pelas características da argamassa aderida e da nova zona de transição formada. Segundo Buttler [9], o grau de hidratação dos resíduos de concreto (idade de reciclagem, comparando com 1 dia e 28 dias) tem influência mais significativa nas propriedades mecânicas do concreto endurecido, resistência à compressão (acréscimo de 3\%), tração (redução de 3\%) e módulo de elasticidade (redução de 6\%). Nestas propriedades, os concretos com agregados reciclados que apresentam pequeno grau de hidratação e grande quantidade de cimento não hidratado alcançam os melhores resultados.

Os teores de argamassa aderida aos agregados reciclados, obtidos a partir de fontes diferentes tem grande variabilidade, podendo estar relacionados com o teor de argamassa original e ao grau de britagem mecânica anterior recebida. No trabalho de Duan e Poon [17] observou que a presença de argamassa aderida ao agregado reciclado levou a uma diminuição das propriedades do agregado, incluindo valores mais baixos de densidade e resistência.

\subsection{Propriedade no estado fresco e endurecido de concretos com agregados reciclados}

A alta absorção do agregado reciclado provoca uma diminuição da trabalhabilidade do concreto que pode ser compensada por meio de pré-imersão de agregado reciclado, tendo em vista que segundo Agrela et al, nos primeiros 10 minutos de imersão do agregado em água, este absorve aproximadamente $85 \%$ da absorção que ocorreria com 24 horas de imersão [18]. No estudo de Buttler [9] a perda de trabalhabilidade do concreto reciclado foi maior quando comparada com o concreto de agregados naturais, pois o agregado reciclado continuou absorvendo água mesmo depois da mistura.

Segundo Levy [12], o concreto com RCD de concreto não teve alteração significativa na demanda de água, porém quando utilizado o RCD de cerâmica, foi visível a necessidade maior de água para se manter a consistência. Este fato pode ser atribuído a maior absorção de água do agregado cerâmico(11,7\% para agregado cerâmico contra $5,4 \%$ para agregado de concreto) e sua maior lamelaridade. Essa lamelaridade provém do fato da alvenaria possuir resistência inferior ao concreto e quando da britagem produzir quantidade maior de material lamelar. No trabalho de Lovato [19], os concretos contendo maior quantidade de cerâmica e argamassa demandaram maior quantidade de água para alcançar determinada trabalhabilidade e quanto maior o teor de substituição do agregado graúdo reciclado, maior a relação água/cimento (acréscimo de 10\% para agregado miúdo e de $15 \%$ para o agregado graúdo). 
No estudo realizado por Leite [8], a relação entre consistência e fator a/c, teve comportamento inverso aos concretos convencionais, pois quanto maior a relação a/c, menor o valor do abatimento obtido, isto pode ser explicado se considerar que as misturas com maior relação água/cimento possuem menor quantidade de cimento e assim tendem a ser mais ásperas e apresentar maior travamento. Quando analisado o abatimento em função da relação água/cimento e proporção de agregado graúdo reciclado, verificou-se neste mesmo estudo que quanto maior o teor de agregado e quanto maior a relação água/cimento, menor foi o abatimento apresentado pelas misturas de concreto. Admite-se que a combinação do baixo consumo de cimentos dos traços pobres com o alto teor de agregados rugosos e irregulares tende a intensificar a queda no valor de abatimentos de concretos.

Leite [8] também analisou a influência do agregado miúdo e do agregado graúdo de RCD no abatimento do concreto e observou que para baixos teores de agregado graúdo, a incorporação de agregado miúdo aumenta os valores de abatimento, provavelmente devido ao aumento na quantidade total de finos da mistura. Porém para altos teores de agregado miúdo, a influência negativa deste material é maior que o aumento do teor de finos, causando uma tendência de redução de abatimento. Este evento ocorre para concretos com relação água/cimento menor que 0,60 , pois quando esta relação é maior não importa a proporção entre os agregados. Nestas condições o abatimento apresentará valores menores devido à escassez de pasta para lubrificar as partículas.

No caso de concretos com agregados naturais, geralmente densos e resistentes, a resistência está influenciada pela porosidade da matriz e da zona de transição. Contudo, quando do estudo de concretos com agregados reciclados, acredita-se que a porosidade deste passe a ter um papel importante na determinação da resistência do concreto. No trabalho de Carrijo [6], observou que no concreto endurecido, a resistência a compressão dos concretos reciclados reduziu a medida que a massa específica do agregado diminuiu (redução de $38 \%$ para fator a/c de 0,40 e $30 \%$ para fator a/c de 0,67 ). Para concretos com baixo fator água/cimento, o agregado reciclado se torna o componente mais fraco, limitando a resistência do concreto (para uma mesma densidade, a redução do fator a/c de 0,40 para 0,67 correspondeu a uma redução da resistência em até 49\%) [6]. A presença de fases mais porosas e de menor resistência mecânica, como argamassas e produtos de cerâmica vermelha e de revestimento, provoca uma redução da resistência dos agregados e um aumento da absorção de água [20].

Os concretos com agregados reciclados respeitam a tendência de comportamento da resistência a compressão da Lei de Abrans, ou seja, quanto maior a relação água/cimento, menor a resistência. O agregado graúdo reciclado exerce maior influência sobre a resistência à compressão que o agregado miúdo reciclado e todos os concretos com agregado reciclado apresentam valores de resistência inferiores ao do concreto de referência. $O$ agregado reciclado apresenta maior rugosidade, 0 que contribui para melhorar a aderência; granulometria mais contínua e maior quantidade de finos, que diminuem a segregação, ajudam no efeito empacotamento e contribuem para o fechamento dos vazios. Como o agregado reciclado também possui maior absorção pode haver, ainda, maior aderência entre a pasta e o agregado através da absorção da pasta e precipitação dos cristais de hidratação nos poros do agregado. 
No caso do agregado miúdo, todos estes fatores podem ser benéficos à resistência do concreto, pois além da melhoria na zona de transição, o agregado miúdo contribui também para o aumento da rigidez da matriz. Todavia, com o agregado graúdo, apesar de também ocorrer uma melhoria na zona de transição, o grão do agregado é mais frágil em relação ao restante do sistema e a falha pode ocorrer no agregado devido a sua maior dimensão [12]. Uma vez que as características da zona de transição na interface tem maior efeito na resistência à tração do concreto, em comparação à resistência à compressão, espera-se que, com uma dada dosagem de concreto, qualquer alteração nas propriedades do agregado graúdo venha a influenciar a razão entre resistência à tração e à compressão do material. Um decréscimo na dimensão do agregado graúdo, a uma dada relação água/cimento, aumenta a razão entre a resistência à tração e à compressão [1].

Além da resistência a compressão outra propriedade relacionada a durabilidade é a deterioração por desgaste superficial. No trabalho de Andrade [21], o desgaste superficial pode ser originado por efeito de abrasão (em pisos e pavimentos) e erosão e cavitação (em obras hidráulicas ou estruturas que estejam em contato com fluidos em movimento). A resistência ao desgaste do concreto por abrasão está integralmente relacionada à qualidade da camada superficial. Portando, a resistência da superfície deve ser maximizada, por meio do emprego de uma pasta de cimento e de um agregado que permitam resistir às solicitações de desgaste.

Lovato [19] observou que a resistência à tração de concretos com agregado reciclado apresentou comportamento semelhante à resistência à compressão, quando verificado a relação água/cimento em comparação com o concreto de referência. Com relação à dimensão do agregado, o comportamento foi o inverso, ou seja, o agregado graúdo reciclado exerceu maior influência negativa sobre a resistência à tração que o agregado miúdo reciclado (redução da resistência de 18,3\% para agregado miúdo e 25,5\% para agregado graúdo).

O módulo de elasticidade do concreto é outra propriedade que está relacionado à durabilidade do concreto e está intrinsecamente relacionado à massa específica, à fração volumétrica, ao módulo de elasticidade do agregado e da pasta de cimento e às características da zona de transição. O módulo de elasticidade da matriz da pasta de cimento é determinado por sua porosidade. Em geral, vazios capilares, microfissuras e cristais orientados de hidróxido de cálcio são relativamente mais comuns na zona de transição na interface do que na matriz da pasta; por isso tem papel importante na determinação das relações tensão-deformação do concreto [1].

Quando há a substituição do agregado natural pelo agregado reciclado, observa-se uma redução do módulo de elasticidade. Em concretos onde o agregado substituído é o graúdo observa-se um maior efeito na perda do módulo de elasticidade do que se substituir o agregado miúdo. No estudo desenvolvido por Cabral et al. [22], o agregado graúdo de cerâmica vermelha apresentou a menor massa específica e a maior absorção de água de todos os agregados utilizados (mais poroso) e exerceu a maior influência sobre o módulo de deformação (redução do módulo em $22 \%$ para $50 \%$ de agregado reciclado e redução de $44 \%$ para $100 \%$ de agregado reciclado). 0 agregado miúdo de concreto apresentou elevado teor de rocha natural em sua composição, resultado da britagem do concreto com agregado natural, possuindo uma elevada massa específica e menor absorção de água, consequentemente exercendo menor influência sobre o módulo. No trabalho de Lovato [19], o módulo de elasticidade de concretos com agregados reciclados, independentemente da 
fração, foi menor que o do concreto de referência (chegando a valores de até $50 \%$ de redução do módulo de elasticidade). O aumento da relação água/cimento também reduziu o módulo de deformação.

Com relação a retração no concreto, Lye et al. [13], analisaram resultados obtidos em 118 artigos e verificaram que em concretos com agregado reciclado de concreto comparados aos concretos com agregado natural, a relação a/c exerceu grande influência sobre a retração por secagem, sendo que quanto maior a relação água/cimento do concreto, maior é a retração. A retração aumentou à medida que houve a substituição de agregado natural pelo agregado reciclado (seja ele graúdo ou miúdo), tal efeito é coerente e pode ser explicado em função da maior porosidade e do menor módulo de deformação dos agregados reciclados e da consequente menor restrição a deformações do concreto propiciada pelos mesmos. Outra possível explicação para esse fenômeno seria a maior demanda de pasta de cimento por parte desses concretos para que se obtenha um mesmo grau de empacotamento. Segundo Cabral et al. [23], a substituição do agregado miúdo produziu um efeito maior sobre a retração por secagem do que a substituição do agregado graúdo (aumento na retração por secagem de 69\% para agregado miúdo e $43 \%$ para agregado graúdo).

\subsection{Zona de transição do concreto com agregado reciclado}

O concreto pode ser entendido como um material constituído de partículas de agregado, envolvidos por uma matriz porosa de pasta de cimento, com uma zona de transição entre as duas fases, constituída de características próprias. No estudo da microestrutura do concreto, a interface pasta/agregado torna-se essencial, por distinguir a aderência de natureza química relativa às ligações cristalinas entre a pasta e agregado e a aderência mecânica devido à rugosidade superficial dos agregados [3].

Em concretos convencionais a zona de transição pasta/agregado é devida a película de água que se forma ao redor dos agregados durante o processo de exsudação de água no concreto, aumentando a relação água/cimento desta área. Devido a isto, os produtos cristalinos formados apresentam tamanho relativamente maior que os mesmos produtos existentes na matriz, tornando a estrutura na interface mais porosa dificultando assim o preenchimento dos vazios iniciais existentes. Devido ao espaço microestrutural nesta interface, os cristais de hidróxido de cálcio, que tem baixa resistência, crescem muito mais e apresntam uma orientação preferencial, 0 que é um aspecto favorável à propagação de fissuras, podendo reduzir a resistência de ligação entre a matriz e o agregado, influenciando nas propriedades mecânicas. Já em concretos com agregados reciclados, que possuem uma textura mais rugosa, há uma melhoria da zona de transição, pois o agregado poroso atrai a migração de íons que tornam esta região mais densa e melhoram o intertravamento mecânico entre agregado e matriz [8].

Nas análises microestruturais de concretos com agregado natural, pode-se observar o perfeito destacamento entre a pasta e o agregado, enquanto que no concreto com agregados reciclados a matriz e a zona de transição praticamente se confundem. Os produtos de hidratação cobrem a superfície dos agregados reciclados, densificando a zona de transição, constatando a formação de produtos de hidratação na superfície rugosa do agregado devido à absorção da pasta de cimento pelo material reciclado. Este fato que contribuiu para aumentar a aderência 
pasta/agregado, diminuindo o tamanho e a dimensão de fissuras, que possam ainda se formar, mas que, no seu conjunto, prejudicariam muito menos a resistência do concreto reciclado [8].

No trabalho de Leite [8] observou-se uma tendência à rápida evolução da hidratação do concreto com agregado reciclado, que deve ser resultado da taxa de absorção mais alta do agregado, que diminui a quantidade de água da mistura, fazendo com que os cristais de etringita e de hidróxido de cálcio formados cresçam menos, tornando a pasta mais densa. Outro fator observado foi um efeito de cura interna tardia no concreto, permitindo que boa parte da água da mistura presente no agregado esteja disponível para as reações de hidratação continuem acontecendo. Leite [8] observou também uma melhora na zona de transição de concretos reciclados com maiores relações água/cimento quando comparados a zona de transição de concretos convencionais com semelhantes proporções. Todo 0 conjunto passou a atuar na absorção e distribuição de tensões de forma semelhante, ajudando a aumentar a resistência dos concretos reciclados com altas relações água/cimento.

\subsection{Durabilidade do concreto com agregado reciclado}

Os efeitos físicos que influenciam negativamente a durabilidade do concreto incluem desgaste da superfície, fissuração devida à cristalização de sais nos poros e exposição a temperaturas extremas. Os efeitos químicos deletérios incluem a lixiviação da pasta de cimento por soluções ácidas e reações expansivas envolvendo ataque por sulfato, reação álcali-agregado e corrosão nas armaduras (através da carbonatação ou por ingresso de íons cloretos ou sulfatos) [1].

No trabalho de Levy [12] foi observado que a carbonatação e a difusão de $\mathrm{CO}_{2}$ está mais relacionada a relação a/c e ao consumo de cimento do que com ao tipo de agregado reciclado utilizado (independente da granulometria ou origem, alvenaria ou concreto). A conclusão que Levy [12] apresenta em seu estudo é de que concretos produzidos com agregado miúdo reciclado de alvenaria ou agregado graúdo reciclado de concreto, na proporção de 50\%-50\% em massa, seriam mais duráveis que o concreto de referência.

Os agregados reciclados podem conter contaminações oriundas do material de origem, ou devido a manuseio posterior. Estes contaminantes podem afetar tanto a qualidade técnica do produto contendo o reciclado quanto significar riscos ambientais [20]. Os principais compostos de agregado reciclado que apresentam riscos ambientais após a aplicação desses agregados como materiais de construção civil são os materiais cerâmicos (tijolos e telhas) e resíduo de gesso, porque eles demonstraram ter uma relação direta com altos níveis de cromo e sulfato [24].

No estudo de Rodrigues et al. [27], foi analisado os teores de cloreto e sulfato solúvel em água e os agregados se mostraram dentro dos limites de norma $(1 \% \mathrm{em}$ relação a massa de cimento), porém quanto a conteúdo de contaminantes leves, não houve enquadramento (máximo de $0,5 \%$ em massa), pois as usinas da região não tem equipamento de separação de alta tecnologia. Alguns dos agregados não atenderam o especificado em norma, sendo que os compostos que afetam negativamente as características dos agregados são: gesso, relacionado ao teor de sulfato solúvel em ácido, argilas, que dão um alto teor de finos, e cimento, relacionado à maior absorção de água. 
A presença de gesso em agregados reciclados tem efeito sobre a qualidade técnica do material. Devido à sua solubilidade, a sua baixa dureza e a baixa densidade, tem efeito negativo na qualidade do agregado. Estas propriedades impedem o uso de concretos que contenham gesso como material para uso em fundação ou em aplicações associadas ao cimento, pois um excesso de sulfatos poderia gerar reações que provoquem expansão com redução na resistência do concreto e consequente deterioração do material [25]. Porém Godinho-Castro et al. [26] complementa esta informação sugerindo que a incorporação de resíduos de gesso na produção de blocos cerâmicos em até $20 \%$, seria viável sem causar impacto técnico adverso (ou seja, mudança na qualidade do produto) e impacto ambiental. Observa-se que o estudo de agregados reciclados contaminados com gesso vai depender de alguns fatores, principalmente relacionado a finalidade de utilização e o percentual de gesso presente no agregado, demonstrando que o tema ainda não é consenso, necessitando de estudos adicionais.

\section{Considerações finais}

Neste trabalho pode observar que muitas características dos agregados naturais analisadas para a obtenção de concretos com boa durabilidade, foram verificadas nos agregados reciclados. A diferença é que algumas destas características como porosidade, densidade, absorção e forma dos grãos possuem particularidades que demandam uma preocupação extra no momento da dosagem do concreto. Muitas destas preocupações estão relacionadas à relação água/cimento efetiva, pois os concretos com agregados reciclados demandam mais água para obter a mesma trabalhabilidade que os concretos com agregados naturais.

Foi observado também que o agregado reciclado influencia as propriedades do concreto no estado fresco e no estado endurecido seguindo os mesmos preceitos do agregado natural, ou seja, um maior fator água/cimento, ou maior porosidade do agregado acarretara em perda das propriedades mecânicas. Quanto a dimensão do agregado, muitos estudos demonstraram vantagens do uso do agregado graúdo reciclado, em relação ao agregado miúdo. Porém estes dados variam muito de um trabalho para o outro, pois dependem de outros fatores envolvidos, como forma do grão, presença de impurezas ou contaminantes, quantidade da argamassa aderida, constituição do agregado, porcentagem de material pulverulento, entre outros. Estes fatores estão relacionados a forma de beneficiamento do agregado, origem do resíduo de construção e qualidade do processamento e separação que podem variar a cada lote. Porém o que o estudo mostra é que já se conhece 0 comportamento dos agregados reciclados e qual é a sua influência nas propriedades dos concretos com eles fabricados, sendo assim controlando o processo de beneficiamento do agregado reciclado, pode-se produzir agregados reciclados de boa qualidade que irão produzir concretos com boa durabilidade.

\section{Referências}

[1] MEHTA, P. K.; MONTEIRO, P. J. M. Concreto: estrutura, propriedades e materiais. 1a Edição. São Paulo: IBRACON, 2008. 674 p.

[2] ACl Committee 201, 2001, "Guide to Durable Concrete (ACl 201.2R-01)," American Concrete Institute, Farmington, Hills, Mich. 41p. 
[3] PAULON, V.A. A microestrutura do concreto convencional. CONCRETO, Ensino, Pesquisa e Realizações. Ed. G.G. Isaia. São Paulo: IBRACON, 2005. 2v. 1600p. 583-604 ISBN: "'85-98576-04-2

[4] ANDRADE, T. Patologia das Estruturas. CONCRETO, Ensino, Pesquisa e Realizações. Ed. G.G. Isaia. São Paulo: IBRACON, 2005. 2v. 1600p. 953-983 ISBN: "'85-98576-04-2

[5] SBRIGHI NETO, C. Agregados para concreto. CONCRETO, Ensino, Pesquisa e Realizações. Ed. G.G. Isaia. São Paulo: IBRACON, 2005. 2v. 1600p. 323-343 ISBN: "'85-98576-04-2

[6] CARRIJO, P.M. Análise da influência da massa específica de agregados graúdos provenientes de resíduos de construção e demolição no desempenho mecânico do concreto. São Paulo, 2005. 129p. Dissertação (Mestrado) - Escola Politécnica, Universidade de São Paulo.

[7] GOMES, P.C.C.; RODRIGUES, C.C.; ALENCAR, T.F.F. Concrete produced with recycled aggregates. Revista IBRACON de estruturas e materiais, v. 5, n. 5, p. 692-701, 2012.

[8] LEITE, M.B. Avaliação de propriedades mecânicas de concretos produzidos com agregados reciclados de resíduo de construção e demolição. Tese (Doutorado). UFRGS, 2001.

[9] BUTTLER, A. M. Concreto com agregados graúdos reciclados de concreto - influência da idade de reciclagem nas propriedades dos agregados e concretos reciclados. Dissertação (Mestrado). EESC-USP. Departamento de Engenharia de estruturas. São Paulo, 2003. 220p.

[10] GÓMEZ-SOBERÓN, J.M.V. Porosity of recycled concrete with substitution of recycled concrete aggregate: an experimental study. Cement and Concrete Research, Vol. 32, p. 1301-1311, 2002.

[11] MARTÍN-MORALES, M.; ZAMORANO, M.; RUIZ-MOYANO, I.; VALVERDEESPINOSA Characterization of recycled aggregates construction and demolition waste for concrete production following the Spanish Structural Concrete Code EHE-08. Construction and Building Materials, v. 25, n. 2, p. 742-748, 2011.

[12] LEVY, S.M. Contribuição ao estudo da durabilidade e concretos produzidos com resíduos de concreto e alvenaria. São Paulo-SP, 2001. 194 p. Tese (Doutorado). Escola Politécnica da Universidade de São Paulo.

[13] LYE, C.; DHIR, R.K.; GHATAORA, G.S. Shrinkage of recycled aggregate concrete. Structures and Buildings 169. 2016. Issue SB 12. Pages 867-891.

[14] EXTEBERRIA, M.; VÁZQUEZ, E.; MARÍ, A.; BARRA, M. Influence of Amount of Recycled Coarse Aggregates and Production Process on Properties of Recycled Aggregate Concrete. Cement and Concrete Research. 37, 735742. 2007.

[15] ULSEN, C.; KAHN, H.; HAWLITSCHEK, G.; MASINI, E.A.; ÂNGULO, S.C.. Separability studies of construction and demolition waste recycled sand. Waste Management, v. 33, n. 3, p. 656-662, 2013. 
KRUGER, P.; PEREIRA, E.; CHINELATTO, A. S. A., INFLUÊNCIA DO AGREGADO RECICLADO NA DURABILIDADE DO CONCRETO: UMA REVISÃO DA BIBLIOGRAFIA. $2^{\circ}$ Simpósio Paranaense de Patologia das Construções ( $2^{\circ} \mathrm{SPPC}$ ), artigo 2SPPC1021, pp. 253-265, 2017. DOI: 10.4322/2SPPC.2017.021

[16] VEGAS, I.; BROOS, K.; NIELSEN, P.; LAMBERTZ, O.; LISBONA, A. Upgrading the quality of mixed recycled aggregates from construction and demolition waste by using near-infrared sorting technology. Construction and Building Materials, v. 75, p. 121-128, 2015.

[17] DUAN, Z.H.; POON, C.S. (2014), "Properties of recycled aggregate concrete made with recycled aggregates with different amounts of old adhered mortars". Materials and Design, Vol. 58, pp.19-29.

[18] AGRELA, F. et al. Limiting properties in the characterisation of mixed recycled aggregates for use in the manufacture of concrete. Construction and Building Materials, v. 25, n. 10, p. 3950-3955, 2011.

[19] LOVATO, P.S. Verificação dos parâmetros de controle de agregados reciclados de resíduos de construção e demolição para utilização em concreto. Porto Alegre, 2007. 180p. Dissertação (Mestrado). PPGEC-UFRGS.

[20] JOHN, V.M; AGOPYAN, V. Reciclagem de resíduo da construção. São Paulo, $2000.13 p$.

[21] ANDRADE, T. Tópicos sobre durabilidade do concreto. CONCRETO, Ensino, Pesquisa e Realizações. Ed. G.G. Isaia. São Paulo: IBRACON, 2005. 2v. 1600p. 583-604 ISBN: "'85-98576-04-2

[22] CABRAL, A.E.B. et al. Determinação da influência do tipo de agregado reciclado de resíduo de construção e demolição sobre o módulo de deformação de concretos produzidos com agregados reciclados. Ibracon structures and materials journal, v. 1, n. 2, p. 171-181, 2008.

[23] CABRAL, A.E.B.; SCHALCH, V.; MOLIN, D. Modelagem da retração por secagem de concretos produzidos com agregados reciclados. Ibracon structures and materials journal, v. 3, n. 1, p. 1-23, 2010.

[24] DEL REY, I.; AYUSO, J.; GALVIN, A.P.; JIMENEZ, J.R.; LOPEZ, M.; GARCIAGARRIDO, M.L. Analysis of chromium and sulphate origins in construction recycled materials based on leaching test results. Waste Management, v. 46, p. 278-286, 2015.

[25] VRANCKEN, K.C., LAETHEM, B. Recycling options for gypsum from construction and demolition waste. Waste Materials in Construction. Ser. 1, 325-331. doi:10.1016/S0713-2743(00)80045-8, 2000.

[26] GODINHO-CASTRO, A.P., TESTOLIN, R.C., JANKE, L., CORRÊA, A.X.R., RADETSKI, C.M. Incorporation of gypsum waste in ceramic block production: Proposal for a minimal battery of tests to evaluate technical and environmental viability of this recycling process. Waste Management, v. 32, n. 1, p. 153-157, 2012.

[27] RODRIGUES, F.; CARVALHO, M.T.; EVANGELISTA, L.; DE BRITO, J. Physical-chemical and mineralogical characterization of fine aggregates from construction and demolition waste recycling plants. Journal of Cleaner Production, v. 52, p. 438-445, 2013. 